Towards a New Paradigm of Healthcare: Addressing Challenges to Professional Identities through Community Operational Research

Mike Walsh ${ }^{\mathrm{a}, *}$

Markus G Kittler ${ }^{\text {a,b }}$

Dawn Mahal ${ }^{a}$

a Stirling Management School

University of Stirling

Stirling

FK9 4LA

United Kingdom

${ }^{\mathrm{b}} \mathrm{MCl}$ Management Center Innsbruck

Internationale Hochschule

Universitaetsstrasse 15

A-6020 Innsbruck

Austria

Accepted for publication in European Journal of Operational Research by Elsevier. The published version can be found at: https://doi.org/10.1016/j.ejor.2017.05.052

*Corresponding author.

Tel 0044 (0) 1786467322

email:m.p.walsh@stir.ac.uk 


\title{
Towards a New Paradigm of Healthcare: Addressing Challenges to Professional Identities through Community Operational Research
}

\begin{abstract}
Healthcare worldwide faces severe quality and cost issues, and the search for sustainability in healthcare establishes a grand challenge. Public interest is growing in a systemic re-conceptualizing of healthcare, from primarily a consumerist problem of individual need for treatment to a need for communities themselves to become more effective in systemic prevention, coping and caring. In community led approaches, scarce resources are moved away from ever-increasing consumerist services to empower, develop and enable communities to plan their own health and community improvements in mutually interdependent patterns of care often seen as 'co-production'. This approach is exemplified by the innovative NUKA system of community led healthcare which originated in Alaska and which was trialled in Scotland in 2012, where it did not achieve similar acclaim as in the United States. The Scottish NUKA trial was due to run for six months and initially appeared to be working well, but opposition from professionals meant the trial was ended early. Our research found that omitting to account for the strong professional identity of GPs and other practice staff was instrumental in the failure of the trial. Beyond deficiencies inadequately considering professional identities, the trial also failed to engage the community and its patients as owners and architects of the system. We argue that the root cause of these problems, was a more general critical systemic failure to manage participatory boundaries and associated identities. Community Operational Research practitioners have developed relevant theories, methodologies and methods to address issues of participation and identity, so could make a significant contribution to opening up new solutions for community led healthcare.
\end{abstract}

\section{Keywords}

OR in health services, Community Operational Research, Healthcare, professional identity, boundary critique. 


\section{Community Operational Research and healthcare}

It is over three decades since Jonathan Rosenhead (1986), when President of the Operational Research Society, coined the term 'Community Operational Research' (COR), and substantially raised the profile of community-based interventions, especially in the UK. The relationship between COR and the work of health and social care professionals, managers and other workers, as well as those using health and social care services, is indicated by the growing number of published empirical examples of COR applied to diverse health and social care problems. A prominent early example is Ritchie et al's (1994) collection of 26 studies in community works, a substantial part of which deals with such topics as health needs assessment (Pepper, 1994), health strategy planning (Friend, 1994), maternal healthcare (Moullin, 1994) and also with vital cross-cutting health and social care themes such as community care (Vahl, 1994) and evaluation (Taket, 1994; later further developed by Boyd et al, 2001, 2007). Since this key publication, others have addressed topics including healthcare quality improvement (Gregory et al, 1994; Walsh \& Hostick, 2004), diversion from custody for mentally disordered offenders (Cohen \& Midgley, 1994), mental health and employment (Midgley \& Milne, 1995), family health (Taket \& White, 2004), sustainability and health (Waltner-Toews et al, 2004), community health schemes in developing countries (Smith et al, 2009) and critical decisions in the care of older people (Sommer \& Mabin, 2015). To this may be added substantial theory developments, such as those of Frerichs et al (2016) and Midgley (2006).

The need for community-based participatory research and systems science to address health disparities has recently been highlighted by Frerichs et al, (2016). They argue that systems approaches have not often been combined with community-based participatory research, and they point to the value of the growing Community Operational Research (COR) literature. Nevertheless, COR as an approach to healthcare improvement remains relatively unknown to healthcare professionals compared with the many heavily promoted initiatives from quality improvement, such as those listed by Powell et al (2009), which include, for example, Lean, Business Process Reengineering and the very high profile Institute for Healthcare Improvement's '100,000 lives'campaign (Berwick et al, 2006). But after decades of attempts to improve quality and yet contain costs, almost all health services around the world are faced with diverse and severe challenges. We argue that COR can contribute a timely, systemically consistent, effective and vital response to these challenges by helping to create more sustainable health and social care through community-led health and social care systems. Our recent research focuses on the obstacles to systemic community- 
led planning of health and social care arising from issues of social and professional identity. We suggest COR can help communities to overcome these obstacles by systemically addressing social and professional identity in community led healthcare.

Our paper is addressed at a heterogeneous audience: it is argued to be of relevance for the COR community, contributing to the ongoing debates focussed around health and social care, and discussing the merits of an alternative paradigm of healthcare delivery. It is also directed towards health and social care scholars, professionals and policy makers. While such a diverse target audience poses challenges to communication (Kittler, 2017), we see this as a worthy exercise to foster crosspollination and bring the two communities closer together on a highly relevant and timely challenge.

We will begin by reviewing the severe nature of the challenges in healthcare, to which we argue COR can play an important role in fundamentally changing the conception, production, delivery and consumption of both health and social care. We will then assess the role of professional identity in the failure of a community led healthcare initiative: a trial of the Alaskan NUKA system in Scotland. Finally, we discuss how COR can address systemic resistance to change in healthcare by incorporating social and professional identity in COR led systemic transformations.

\section{Quality and cost 'chasms' in healthcare}

There is both a sense of great progress in medical care and yet deepening worries around the world about widespread quality and cost issues associated with health and social care. There is international recognition of pervasive health inequalities, both within and between countries (e.g., Marmot \& Bell, 2012). There are acknowledged fundamental weaknesses in developing country health systems (US Government, 2012), and richer country health systems are seen as increasingly costly, with sustainability in doubt. On the latter point, Appleby (2013), a leading health economist at the King's Fund, forecasts that the costs of US healthcare will rise from around 17\% of GDP to what will appear to many people as a staggering 50\% of GDP by 2061 and British health care spending will rise from around $6.8 \%$ of GDP in $2016 / 17$ to as much as $16.6 \%$ by 2061 ; with the cost of long-term care rising from $1.1 \%$ to as much as $2.5 \%$ of GDP in the same period. Yet Appleby's analysis makes important assumptions (ceteris paribus as economists say), not only about long-term rates of growth (which may be much higher or much lower), but also about health technological, social and political factors - and may be, therefore, relatively conservative. In addition to the challenges stemming from a continuously increasing population, a variety of global systemic disruptions are possible. These 
might include the threat posed by antibiotic resistance (Davies, 2013; World Health Organisation, 2014), increasing demand arising from long-term conditions (Barnett et al, 2012), more need for endof-life care for ageing populations (Gomes et al, 2009), and disrupted politics causing changes in spending in the face of international political turbulence. Climate change poses another severe disruptive threat, with immense health consequences within and beyond the timescales of Appleby's analysis (Intergovernmental Panel on Climate Change, 2015). Taken together, without change to the basic nature of healthcare, these possible developments imply that the risk of severe cuts or deterioration in quality in developed countries' healthcare is higher than Appleby (2013) suggests.

Given these enormous pressures, it is an international priority to rationalise healthcare in poorer countries by strengthening health systems, and in richer countries by improving quality whilst getting rid of waste and pursuing synergies and efficiencies. In recent years these kinds of initiatives have been led internationally by the Institute for Healthcare Improvement (IHI), with a focus on crossing the infamous 'quality chasm' (Institute of Medicine, 2001) in healthcare through patient centred care (e.g. Mason \& Kittler, 2010) and high profile patient safety campaigns (e.g. McCannon et al, 2007), typically by applying a Deming (1982) style 'plan-do-check/study-act' cycle. Another focus is the search for technological inventions and innovations in processes, treatments and tools, including new drugs, increasingly advanced treatments such as gene therapy (Kazemi et al, 2016), innovations like the roll out worldwide of the surgical safety checklist (World Health Organisation, 2008) and the innovative use of social media and other digital technologies (Gretton \& Honeyman, 2016).

Unfortunately, innovative developments in improving the delivery of health and social care in developed (and also less developed) country contexts may themselves contribute to cost inflation by either increasing the range of diseases treated or adding to, not substituting for, existing treatments, or simply by contributing to the waste that Berwick \& Hackbarth (2012) estimate is much greater than $20 \%$ of all healthcare expenditure. Indeed, action is needed, and Berwick \& Hackbarth (2012) discuss overtreatment, failures of coordination, reliability and pricing, administrative complexity and fraud and abuse. Similarly, in UK healthcare the Kings Fund see the need to "transform" the National Health Service (NHS) in England by supporting self-management, prevention and better coordination (Naylor \& Curry, 2015). The perceived local lack of sustainability in the NHS is recognised in the government requirement of the entire NHS in England to produce 44 regional sustainability and transformation plans (NHS England, 2016). For instance one plan, that of the North West London Collaboration of Clinical Commissioning Groups (2017), states that "over 30 percent of patients in acute hospitals do not need to be there", and "80 percent of people want to die at home, but only 22 percent do so". They further state that "if we don't take action, there will be a $£ 1.3$ billion shortfall 
by 2021" (p. 5). The action proposed is to move resources from caring for the ill to supporting "patients to stay well and take more control of their own health and wellbeing, as close to home as possible" (p. 2). Yet while the overarching goal seems clear, it is much less obvious how this transformation will be achieved nor what the relationship is between the planners and the planned for which appears to be top-down. For instance, the plan proposes to increase bowel screening uptake from $40-52 \%$ to $75 \%$ by 2020 (p. 23), but this is an efficiency target that does not itself address the sustainability of services. It also does not explain why the uptake of this highly desirable clinical activity is so low. More intriguing is the suggestion that there will be the use of patient activation measures to help patients take more control over their own care, but again the 'how?' is not addressed. The plan is silent on the details of these activities.

In contrast, in developing countries there remain large gaps between goals and achievements and this is mainly blamed on weak health systems (Roberts et al, 2002) failing to deliver what is, at least in theory, already available. Hence, the World Health Organization $(2007$, p. iv) asserts that "the strategic importance of strengthening health systems is absolute". Indeed, the kind of strengthening proposed appears to lead weak health systems towards the quality chasm of unsustainable 'strong' health systems in wealthier, developed countries, exemplified by the US health system or the UK NHS, the affordability of which are frequently discussed. So the search for alternative sustainable approaches to healthcare is seen as internationally urgent in both richer and poorer countries, and one potential approach which we suggest in this paper is a systemic reconceptualisation of health and social care, which would require the kind of understanding of boundary conditions that is commonly found in COR theory and practice (e.g., Midgley et al, 1998, 2007; Midgley, 2000; Boyd et al, 2004; Córdoba \& Midgley, 2006; Midgley \& Pinzón, 2013; Barros-Castro et al, 2015; Helfgott, 2017; Ufua et al, 2017).

\section{Systemic reconceptualising of health and social care}

The seeds of more radical approaches are readily identifiable in the healthcare debate. The international recognition of the social determination of health and welfare, with the conclusion that "social injustice was killing on a grand scale kill" (Commission on Social Determinants of Health, 2008, p. 26) in both richer and poorer countries (see also Marmot \& Bell, 2012), was a landmark moment praised as "courageous" by Navarro (2009), although he also pointedly criticizes the Commission on Social Determinants of Health report for ignoring politics. Another development is the recognition of 
the limitations of the medical deficit model, which focuses on the causation of disease and its diagnosis and treatment, and the emergence of an alternative view based on trying to understand how health is caused by the positive medical or health assets, resources or strengths of individuals and their communities. This salutogenic approach, initially introduced by the sociologist Antonovsky $(1979,1987)$, has been heavily promoted by the Chief Medical Office in Scotland (Burns, 2010). There is increasingly strong evidence of peer influences on individual health behavior (e.g., Christakis \& Fowler, 2008), evidence of the benefits of individual and group involvement and participation in healthcare (Gomes et al, 2009) and the emergence of new healthcare information and communication technologies (Weiner et al, 2013). Moreover, the search for efficiency has inevitably led to attempts to overcome coordination and cost problems by integrating the typically separate systems of health and social care (Naylor \& Curry, 2015). Integration of care is proceeding both in England (NHS England, 2014) and Scotland (Audit Scotland, 2015), and is a key feature of the NUKA system in the US state of Alaska (Gottlieb, 2013).

Taken together, these developments point towards a necessary systemic re-conceptualizing of healthcare from being seen primarily as a consumerist problem of individual need for commodified treatment (exemplified by the US health economy), or as a multi-agency service coordination or integration problem (which recent evidence from the National Audit Office, 2017, shows has not so far yielded the expected financial benefits) to a need, as implied by Alderwick et al (2015), for communities themselves to become more effective in systemic prevention, coping and caring. In such community-led approaches, scarce resources are moved away from ever-increasing and unsustainable consumerist service provision to empower, enable and develop communities to plan their own health and community improvement in mutually interdependent patterns of care often viewed as 'co-production' (e.g. see Scottish Government, 2007). It must be emphasised though that this is not equivalent to intensifying neo-liberal consumerism by simply transferring greater responsibility to individuals for meeting their own healthcare needs within community controlled healthcare. Instead, co-production of healthcare needs to be seen as a critical systemic process mobilising the resources and efforts of individuals, families and groups in co-producing and distributing the benefits of healthcare. Failure to achieve this is likely to increase costs and/or health disparities, as Frerichs et al, (2016) suggest typifies current health systems.

Yet this international acknowledgement of the need for community leadership in healthcare is decades late in coming. Nyswander's (1956) call to start where the people are, acknowledged by the US public health service (Derryberry, 1957), echoes critical perspectives that emphasise moral and practical necessity in deepening engagement in, and control over, socio-economic life. It is striking 
how these insights and their associated developments in healthcare also reflect postwar developments in OR and systems thinking, like that of Churchman and Ackoff (1949), which were coupled with an explicitly ethical perspective (Churchman, 1952), leading Churchman (1970) to argue that a 'sweeping in' of perspectives was necessary, not simply to improve effectiveness, but also for ethical solutions to problems seen as systemic in nature. This was mirrored by Ackoff $(1981,1999)$, for whom the explicitly ethical imperative arises because those affected by a plan should be involved in making it and it is better to plan than be planned for. It is unclear at this time to what extent the 44 sustainability and transformation plans for the NHS in England do, or will adhere to these long established principles.

Echoing these earlier critical and systemic perspectives, as well as more recent work in COR the need for a synergistic, complementary blending of community-based participatory research (CBPR) and systems science perspectives to address health disparities are highlighted by Frerichs et al, (2016). They identify five synergies between CBPR and systems science: paradigmatic (systemic logic coupled with community perspectives), socioecological (working at multiple system levels to overcome health disparities), capacity building (system models informing community work), co-learning (building on participatory knowledge generation and utilization) and translational (implementation to reduce health disparities). Tellingly, they emphasise that CBPR works by building on strengths at multiple levels, from individuals to organisations, which are highly consistent with the salutogenic perspective noted earlier. They argue that the failure to account for systemic aspects of health policy implementation can lead to policy resistance. Indeed, we argue later that failure to address a critical systemic feature of the trial of the NUKA system in Scotland - the shaping of vital systemic boundaries by professional identity - was a factor in the failure of the trial.

\section{COR and social identity}

For decades, COR scholars have focused on the role of boundary exploration as a feature of systemic intervention, and the critique of boundaries that include, exclude or marginalise either people or issues of concern is an important task in COR practice. The importance of identity in shaping boundaries is gradually gaining recognition in our research community (e.g., see Boyd et al, 2004; Córdoba, 2001; Córdoba \& Midgley, 2006; Shen \& Midgley, 2007). Midgley et al, (2007) see the identities of COR practitioners as an often missed influence on the way boundaries are determined. Identities, they argue, are ascribed by actors who are interpreting system boundaries under the 
influence of power relationships, and both identities and power relationships legitimate actor roles, which in turn bring behavioural expectations. Thus, boundary critique (see e.g. Midgley et al, 1998 for a discussion of boundary critique theory and practice, establishing the need to identify and access diverse stakeholder views, including those of marginal groups), and critical self-reflection by COR practitioners on their inevitably-embedded non-neutral roles in boundary formation, can enhance systemic awareness. Midgley et al, (2007) espouse a pluralist view, rejecting the exclusivity of any particular identity theory in boundary critique. However, their views are highly consistent with the specific identity theory that has proven useful in our empirical attempt to explain the failure of a NUKA trial in Scotland.

We adopt key ideas from social identity research to further support our argument. Social Identity Theory (SIT) was created to explain and explore inter-group relations and provide a theoretical understanding of the relationship between selves and groups (Tajfel \& Turner 1979; Turner, 1975; Van Knippenberg \& Hogg, 2003). SIT assumes people tend to classify themselves and others into social groupings or categories defined by identifying 'characteristics', such as gender, age and religion (Tajfel \& Turner, 1986). Haslam (2004) argues that self-identity develops and deepens as individuals identify with groups and place value upon membership of them. Thus identification with a group is assimilated into one's own self-concept (Tajfel \& Turner 1979) and this influences behaviour (Postmes et al, 2005). The situation is made more complicated because individuals may identify explicitly or implicitly with multiple groups which produces consequent tensions, inconsistencies or even outright pathologies - such as the doctor who commits serial murders (Gilleard, 2008). So in any system change or interventions, the overt or covert identities of those affected or involved will be influential on both the process and the outcome.

Within this theory, professional identity has emerged as an important concept in its own right (e.g., see Cox et al, 2016; Cruess et al, 2016; Helmich et al, 2017; Ibarra, 1999; Moss et al, 2014). In general, professional identity can be said to be "an individual's self-definition as a member of a profession and is associated with the enactment of a professional role" (Chreim et al, 2007, p. 1515). It has been argued that a professional identity should be considered to be a core identity, overriding other identities (Costello 2005). Clouder et al (2012) have also proposed that, when multiple identities are in evidence simultaneously, they may appear hierarchical, and the identity which is the best fit with the context will take precedence. So in a professional context, the professional identity may be expected to take precedence over other identities. This is particularly important in the context of healthcare, which is dominated by clinical and managerial professionals and, as we have argued, in which radical change is to be expected due to the unsustainability of the status quo. 
With change required, additional concerns stem from Coram and Burnes' (2001) observation that a substantial number of organisational transformation projects fail. Burnes and Jackson (2011) consider one vital factor in this to be a lack of alignment between the value systems of the change intervention and those undergoing the change. This is of particular relevance to the UK health service, given that there is generally considered to be a mismatch between the values of NHS clinicians and NHS management which, as Drummond-Hay and Bamford (2009) argue, is at least partly due to clinicians wanting perfect healthcare but chief executives wanting efficiency and cost effectiveness. But this could also be seen as an oversimplification. For instance, Dutton, Dukerich \& Harquail (1994) suggest that, for a change in professional behaviour to occur it needs to be perceived as compatible with the existing professional identity; it needs to fulfil individuals' needs for selfcontinuity, self-distinctiveness and self-enhancement, and be consistent with accepted professional ideals and boundaries. According to Thorne (2002), the medical profession traditionally adapts to change by initially being resistant, then subsequently it negotiates the meaning of the change, and finally incorporates it into the existing structures and processes of the profession. These changes then become reinterpreted as the profession use's its cultural and social authority to re-define and present the changes back to its members.

It is widely accepted that defined and accepted professional boundaries are not fixed; they can be influenced and changed, but it means that professions strive for control over boundaries. This sheds light on healthcare, where broadened participation has substantially moved the old boundaries defined by clinical professionals (primarily in terms of a medical model giving rise to a 'consumerist sickness management system'), to a wider conception of health systems. The new boundaries may extend as far as redefining patients (and their carers, families and social networks) as key elements of the system involved in the co-production of healthcare. This approach is exemplified by the innovative NUKA system (Gottlieb, 2013) of community led healthcare, which originated in Alaska in the United States and was trialled in Scotland in 2012. What boundary and identity analysis also reveals is how and why community led healthcare may be frustrated in the intense professional context of healthcare, as we all shortly see.

\section{NUKA and the failure of the Scottish trial}

According to Gottlieb (2013), the Southcentral Foundation's "NUKA System of Care', based in Anchorage, Alaska, is a comprehensive healthcare system serving over 60,000 Alaskan native and 
American Indian people who manage and own this system. It is aimed at fostering and maintaining their physical, mental, emotional and spiritual wellness. According to Graves (2013), since NUKA was implemented it has cut hospital A\& E visits by $42 \%$, hospital in-patient days by $36 \%$, speciality care by $58 \%$, and routine doctor visits by $30 \%$, all of which have reduced costs. The ultimate outcome appears to be that Alaskans in the NUKA system are making better use of their resources, thus improving the healthcare for the community. Over the course of 30 years, the health care in this region went from being among the worst in the United States to being hailed as among the best in the world (Collins 2015). It is lauded by Berwick (2011) for exemplifying the way ahead for healthcare improvement. The NUKA initiative was created in the late 1990s out of an existing but inadequate bureaucratic system centrally controlled by the Indian Health Service. This was made possible by Congress legislating for tribal "self-determination" - meaning tribes could own the service providers - after lobbying by the local native community (Gottlieb, 2013). This is remarkable given that the US commitment to private healthcare exemplifies what Midgley (1992) calls a 'sacred' boundary (referring to a boundary which is protected from critique by the marginalization and vilification of other policy options) and the legislative change moves NUKA firmly out of the domain of the 'profane' (vilified) giving the Alaskans something close to a British NHS-style system.

However, unlike the far more patriarchal origins of the NHS, NUKA was created in conjunction with the local community it served, with services provided by an integrated team of doctors, nurses, dieticians, pharmacists, behavioural health consultants and other professionals. Crucially, NUKA is aimed at de-medicalizing healthcare, yet with all members of the clinical team being deemed equally responsible for creating and carrying out patient treatment plans. A broader approach to improving family and community wellbeing is taken, with education, training and community engagement building on the culture of the Alaskan native community and offering traditional forms of (native) healing practices alongside other health and care services (Alderwick et al, 2015). The apparent consistency of the NUKA system with policy in Scottish healthcare (Scottish Government, 2007) led to a trial of the system in an NHS Health Board (NHS Fife) in Scotland in 2012. However, this trial was considered unsuccessful and was ended early. In order to learn from this failure, most of the remainder of this paper introduces and reflects on the Scottish trial and provides a systemic perspective to understand its shortcomings. The paper then ends with a discussion of the opportunities for COR practitioners interested in contributing to the transformation of communityengaged healthcare.

NHS Fife is a comprehensive NHS healthcare provider for 367,000 people in the Scottish region of Fife (Coyle, 2012), with a 2016 budget over $£ 600 \mathrm{~m}$. Like other NHS providers, it is facing high-profile, 
severe financial pressures (Warrender, 2016). In 2012, NHS Fife appointed an implementation team who were convinced that the NUKA system offered a way for the local NHS to remain viable, and they were tasked with organising a trial. A General Practice, 'Tayriver' (a pseudonym), willing to host the trial was recruited. The practice manager at Tayriver coordinated the trial and visited Alaska to see first-hand how NUKA worked. The trial was created with an integrated team of two nurses, the 'championing' GP, a behavioural psychologist and an administrator, to serve one-fifth of the practice population. They were selected randomly from the practice list and invited to public meetings where consent was secured for involvement in the trial. The trial was due to run for six months and if successful was to be extended within the practice and to other practices across the region.

The trial was evaluated after six weeks by the implementation team, and it was found that the NUKA trial clinical practitioners performed more than five times the number of phone consultations and reduced to one-third the number of face-to-face consultations compared with the rest of the surgery team. This was thought to indicate a significant shift from making appointments to managing patients over the phone, freeing up appointment times for the GP in particular and leading to better management of patient demand and reduction of pressure on staff. Both the implementation team and the Tayriver NUKA trial team reported satisfaction with the system. Yet opposition from GPs within the rest of practice meant the NUKA system was not extended as planned, and the trial was ended before the six month period elapsed without reference to the patients who had consented to be involved. The Implementation Team looked for other practices to trial the system, but none of the 58 practices in Fife were willing to do so. The resistance to implementing or even to trial the implementation of an innovative healthcare approach will be examined and discussed below.

According to Alderwick et al, (2015) and Gottlieb (2013), an important feature of the success of NUKA in Alaska was a change in the role of physicians and clinicians in the system of care -i. e. fundamentally changing the physician scientific-medical gate-keeping role that typifies orthodox primary care. Since role indicates identity (Midgley et al, 2007), it was considered that a threat to professional identity may have underpinned resistance to the NUKA trial. To find out if this was the case, an inductive Informed Grounded Theory study (Thornberg, 2012) was carried out with 14 indepth interviews with primary care staff. Interviewing only stopped when a saturation of categories was achieved and the thematic analysis did not seem to generate additional themes nor provide additional insights. Each theme emerged from the incorporation of similar sub-codes and was considered alongside segments of raw data, extracts from field notes, memos, research diary, and supporting literature. The interviews revealed three overarching themes underlying opposition to the trial: 'Shifting Culture', 'Maintaining Professionalism' and 'Resisting De-professionalism'. 
INSERT TABLE 1 HERE

$===$

Shifting culture describes how practice staff felt that the culture of their profession is changing, especially in terms of expectations, role in society and differences between generations. They perceived that wider changes within society, such as ease of access to medical information online, had resulted in changes of attitude to medical professionals: some patients now expect a more equal relationship with their health care providers, and they are less deferential. On a day to day basis, they saw that the work of the practice, the roles of the nurses and doctors, and the expectations placed on them by the media, patients and the Health Board, were changing. Interviewees felt that their daily jobs were getting harder for a number of reasons, including insufficient time, resources, support and facilities. Practice staff talked about the detrimental pressures generated by the GP Contract (British Medical Association Scotland, 2012) and how it has reduced their autonomy, changed the way they interact with patients and increased their workloads. They felt that changes to the way they worked and the new expectations placed upon them were having the effect of fundamentally changing their profession.

Maintaining professionalism described how practice staff strived to maintain excellent professional standards in the face of changes, which were seen to be causing much unrest, stress and staff burnout. During the interviews, some of the most frequently cited changes mentioned were those coming from the new GP Contract. While some Primary Healthcare staff saw the contract as 'good', the majority of GPs, Practice Nurses and Practice Managers felt it was challenging the fabric of primary healthcare, the way doctors and nurses' work and how they regard themselves. Practice staff indicated that they were being asked to do more for the GP Contract, but it was a source of bureaucracy, frustration and stress, with some claiming the system was unwieldy, slow and prone to technological problems - and a major cause of continuing demoralisation in Primary Care.

Resisting deprofessionalism explains how GPs felt they were striving to stop the erosion of their professional roles. Reforms have resulted in new models of governance in hospitals (Ferlie et al, 2012) but these reforms are only slowly filtering through to GP practices. GPs saw themselves as fighting to maintain the boundaries between themselves and other medical professionals. For instance, they are resistant to the idea of Nurse Partners and other health care professionals working 
alongside and with them, rather than being directed by them. It would appear that these doctors were maintaining their professional dominance by delegating routine tasks to other professionals (reducing their workload) while maintaining their control of how and when the tasks were carried out, which served to reinforce the fact that the doctor is still top of the hierarchy. These research findings have a direct consequence for the NUKA trial as a key component of the NUKA system is shared responsibility for patient care, which was resisted by the GPs who refused to give up their decision making autonomy.

The interviews suggested that staff, and particularly GPs, felt that their professional identity was challenged with a number of GPs resisting NHS Fife 'interference' and actively blocking changes perceived as threatening. GPs did indicate a willingness to accept changes to their working practices, but only within what they deemed as reasonable boundaries - which meant no change that appeared to threaten their control or their professional identity. This idea is supported by work done elsewhere by Currie et al, (2012) and Charles-Jones et al (2003) and it suggests that the failure to account for the strong professional identity of the GPs and other practice staff was instrumental in the overall failure of the NUKA trial in Scotland.

Yet it is also striking that the NUKA system in Alaska was developed and implemented primarily by the local community in a situation that appeared to have much in common with Scotland, where there is a strong commitment to values of co-production and partnership (Scottish Government, 2007). On the surface, the trial of NUKA in Scotland seemed appropriate. Indeed, the NHS Implementation Team tasked with carrying out and evaluating the trial, who also visited NUKA in Alaska, were highly convinced and enthusiastic. This makes the failure of the NUKA trial in Scotland not only disappointing, but apparently more surprising. So why, from a COR viewpoint, did the trial not work? Why did professional identity become such an obstacle, and how might COR practitioners address this?

\section{Systemic reflections and lessons for COR}

Midgley et al (2007) suggest 12 indicative strategies for systems practitioners to address issues raised by their own ascribed identities. However, these strategies are also particularly salient for highlighting a number of more general failures of systemic reflection on identity in the NUKA trial in Scotland. In table 2, we contrast the initial and successful NUKA initiative with the failed Scottish trial 
in terms of whether or not each of the 12 strategies was employed. We then briefly comment on each of these.

$==$

INSERT TABLE 2 HERE

$===$

We begin with the failure to explore the relevance of culture in the Scottish NUKA. The culture was 'taken-as-given', with no opportunities either for discussion of the current culture in the practice, or of a new culture which the practice needed to move towards. Exploration here could have swept in the views of patients and their families, as for instance exemplified by the patient-centred-and-led inquiry in primary care reported by Walsh \& Hostick (2004), and also GPs and other practice professionals and staff could have engaged in peer group and multi-group dialogical encounters, as discussed by Gregory et al (1994). To consider culture properly requires sufficient time for relationship building prior to and during the substantive intervention, and this did not occur in the Scottish NUKA trial for either clinicians or patients. Failure to take this time seems to have accentuated the emergence of the threat to GP professional identity as a key stumbling block.

Using established formal as well as informal processes for sharing information about identity is not a clear feature of the accounts of the development of NUKA. It seems that, in Alaska, clinicians were recruited whose professional and social identities were a close match to the needs of the NUKA approach. However, this appears not to have occurred in the Scottish trial. Establishing a strategic partnership with a trusted organisation was a less clear feature of NUKA in Alaska, although the Scottish trial was guided to some extent by the original NUKA, which could in a sense be seen as a trusted organization. However, calling this a 'partnership' might be stretching the truth, as really the Scottish trial was built around accounts of the Alaskan experience without the direct involvement of the Alaskans, In addition, there were also local academic resources were accessed and advice sought. Yet beyond this, it is not clear what other strategic partners were considered, either locally to Tayriver or nationally in Scotland.

Involving trusted individuals in brokering new relationships was a feature of the NUKA in Alaska, as individuals trusted by native Americans brokered new relationships, both locally and with the US Government, to create the new system. The Scottish NUKA trial also involved trusted individuals in the recruitment of a GP and a Practice Manager, but the numbers were small compared with the rest of the practice, from where the resistance came. Ensuring that people with a valued local identity 
and local knowledge are key decision makers failed in Scotland because, although the GP and Practice Manager had local knowledge, our data shows the other GPs did not want the boundaries and values of their practice being determined by the Practice Manager, who was actually regarded as an 'outsider'. Nor did patients have an opportunity to discuss, influence or decide on the roles of any of the key personnel. Their primary role appeared to be that of legitimating 'consent giver', as they were consulted on whether the trial should happen, but were then expected to resume a traditional patient role. Midgley et al (2017) argue that a central feature of COR is the meaningful engagement of communities, and there is a significant question here about whether the engagement of the patients in setting up the NUKA trial was really meaningful.

Recruiting a person to the practitioner team whose identity is closely aligned with that of participants was a vital step in NUKA in Alaska, where clinicians and others seem to have been recruited because of their fit with the needs of the system. In the Scottish trial the GP was already in place as a senior partner, as was the practice manager but these two recruits were insufficient to enable the sustainability and expansion of the trial. Adopting methodological principles that align with participants' identities occurred in NUKA, Alaska, but not in the Scottish trial. Neither did involving participants in the choice and/or design of methods in addition to involving them in the conversations that the methods structure take place. Similarly, using a participative approach to establish an active listening stance did not occur. While this was a vital principle for the success of NUKA in Alaska, it may be that the implementation team for the Scottish trial were over enthusiastic, and either unable or unwilling to take on board the identity issues raised by the trial for the other practice partners and staff.

It can be seen, with hindsight, that sincerely mirroring key aspects of participants' concerns and interests associated with their identity would have presented an opportunity to address the professional concerns of the other GPs and practice staff, and identifying what the participants were looking for in evaluating identity and (sincerely) framing practitioners' presentations of self accordingly would have helped too. Instead, the Scottish trial was created with a fixed agenda that did not take into account the professional or more general social identities of staff and patients, and how the agenda would impact on them.

It is interesting to see, therefore, that those apparently outside the boundary of intervention in Tayriver were able to stop the trial without reference to the patients - they were 'owners' in the terms set out in Soft Systems Methodology (i.e., with the ability to stop the system from working) (Checkland \& Poulter, 2010). This observation also reveals how the participatory boundary of a 
systemic intervention is not a thin line but a region (perhaps of varying thickness) that must itself be subject to criticism and action if the risks posed by others are to be addressed by the participants in a COR project. The NUKA trial could not be insulated or separated from the rest of the Tayriver practice and, applying Midgley's (1992) theory of marginalization processes, the 'sacred' identity of the other GPs in Tayriver was challenged by the introduction of a new identity that those GPs regarded as profane. The ascription of a profane status to the GP and Practice Manager who had welcomed the new identity was aided by both existing tensions between doctors and practice managers more generally (in the context of a 'struggle' for professional dominance) and the marginalization of the other GPs in the Scottish trial, giving them no real say in its remit and implementation. As Midgley and Milne (1995) make clear, when those with the ability to stop a system from working are marginalized, there are likely to be repercussions. In addition, there was no dialogical process owned by patients and other members of the community that would have enabled an evolutionary shift in boundaries - one in which the GP's professional identity could itself have evolved into something new. The trial ended, and with it the chance to transform Tayriver healthcare into a new type of community-led health and social care system, which might well have been more sustainable in the long run than the one that survived this short-term trial.

\section{Conclusion}

Our study shows, from the critical perspective of COR, that the Scottish NUKA trial needed to address professional and more general social identity issues by surfacing them through dynamic and reflexive processes of boundary critique. There is an open question here of course: what if the 'community' had refused the trial? Indeed, there is nothing inevitable about local choices by local people. As a consequence, it is suggested that community-led healthcare cannot simply be imposed, but it can be explored, as the examples of Tayriver and NUKA, Alaska, show. The Scottish NUKA trial succeeded while it lasted, but only from the viewpoint of its two 'champions'. It failed to become the transformative basis of health and social care in Tayriver because of a critical systemic failure to manage participatory boundaries and associated identities. Our case study suggests that everyone involved in or affected by change has social identities that may be challenged in some way. Social identity is not immutable, but any given community or group may be highly resistant even to beneficial change if its identity is threatened. 
Returning to the original motivation of our paper, which is to foster further cross-pollination between the COR community on the one hand, and health and social care scholars, practitioners and policy makers on the other, we have looked at the failed implementation of a health care initiative through the lenses of professional identity and the COR theory of boundary critique. Our paper provides health care practitioners and policy makers with an explanatory approach as to why the trial of a previously successful initiative - contrary to their expectations - was unsuccessful. Communityled healthcare, our insights suggest, needs a high degree of acceptance and engagement by relevant actors to be successful. To achieve this requires facilitated reflection on boundary conditions and an understanding of the importance of processes of marginalisation. This is particularly relevant as community-led approaches are emerging as a way forward for healthcare internationally. We argue that, for these to work as intended, communities and patients, in addition to medical and other professionals, need to be regarded as system owners and architects of the system. Arguably this underpins the success of NUKA, Alaska, which as Nyswander (1956) says, started where the people are. COR practitioners have insights, theories and tools, developed over decades, that can help to address these issues.

Those seeking more information about the methodology and practice of COR are advised to refer initially to the discipline's three most seminal texts Ritchie et al, (1994), Midgley \& Ochoa-Arias (2004), and Johnson (2012). Also see Midgley (2000) for a more philosophical perspective linked into a discussion of methodology and practice. We look forward to a continuing engagement between COR and the various health-related disciplines for the benefit of a successful transformation to community-led healthcare. 


\section{References}

Ackoff, R. L. (1981). Creating the corporate future: Plan or be planned for. Chichester: Wiley.

Ackoff, R. L. (1999). Re-creating the corporation: A design of organizations for the 21st century. Oxford: Oxford University Press.

Alderwick, H., Ham, C. \& Buck, D. (2015). Population health systems. Going beyond integrated care. Retrieved from: http://www. kingsfund. org. uk/sites/files/kf/field/field_publication_file/populationhealth-systems-kingsfund-feb15.pdf

Antonovsky A. (1987). Unravelling the mystery of health. How people manage stress and stay well. San Francisco: Jossey-Bass.

Antonovsky, A. (1979). Health, stress and coping. San Francisco: Jossey-Bass.

Appleby, J. (2013). Spending on health and social care over the next 50 years. Why think long term? London: King's Fund.

Audit Scotland. (2015). Health and social care integration. Edinburgh: Audit Scotland.

Barnett, K., Mercer, S. W., Norbury, M., Watt, G., Wyke, S. \& Guthrie, B. (2012). Epidemiology of multimorbidity and implications for health care, research and medical education: a cross-sectional study. The Lancet, 380(9836), 37-43.

Barros-Castro R, Midgley G and Pinzón L (2015). Systemic Intervention for Computer-Supported Collaborative Learning. Systems Research and Behavioral Science, 32(1), 86-105.

Berwick, D. M. (2011). The moral test. Keynote Presentation at IHI's 23rd Annual National Forum on Quality Improvement in Health Care. Orlando: Institute for Health Improvement.

Berwick, D. M., Calkins, D. R., McCannon, C. J. \& Hackbarth, A. D. (2006). The 100,000 lives campaign: Setting a goal and a deadline for improving health care quality. JAMA, 295(3), 324-327.

Berwick, D. \& Hackbarth, A. (2012). Eliminating waste in US health care. JAMA, 307(14), 1513-1516.

Boyd, A., Brown, M. \& Midgley, G. (2004). Systemic intervention for community OR: Developing services with young people (under 16) living on the streets. In G. Midgley \& A. E. Ochoa-Arias (Eds.), Community operational research: OR and systems thinking for community development (pp. 203252). New York: Springer.

Boyd, A., Geerling, T., Gregory, W., Kagan, C., Midgley, G., Murray, P. \& Walsh, M. (2001). Capacitybuilding for evaluation: A report on the HAZE project to the Manchester, Salford and Trafford Health Action Zone. Centre for Systems Studies: Hull.

Boyd, A., Geerling, T., Gregory, W., Kagan, C., Midgley, G., Murray, P. \& Walsh, M. (2007). Systemic evaluation: A participative, multi-method approach. Journal of the Operational Research Society, 58(10), 1306-1320. 
British Medical Association Scotland. (2012). General practice in Scotland: The way ahead - progress report. Edinburgh: British Medical Association

Burnes, B.,\& Jackson, P., (2011). Success and failure in organizational change: An exploration of the role of values. Journal of Change Management, 11(2), pp. 133-162.

Burns, H. (2010). Annual report of the Chief Medical Officer, Health in Scotland 2009. Retrieved from http://www. gov. scot/Publications/2009/12/16103619/0

Charles-Jones, H., Latimer, J. \& May, C., (2003). Transforming general practice: the redistribution of medical work in primary care. Sociology of Health and IIIness. 25(1), pp.71-92.

Checkland, P. \& Poulter, J. (2010). Soft Systems Methodology. In M. Reynolds \& S. Holwell (Eds.), Systems approaches to managing change: A practical guide (pp. 191-242). London: Springer.

Chreim, S., Williams, B. B. and Hinings, C. B., (2007). Interlevel influences on the reconstruction of professional role identity. Academy of Management Journal, 50(6), 1515-1539.

Christakis, N. \& Fowler, J. (2008). The collective dynamics of smoking in a large social network. New England Journal of Medicine, 358(21), 2249-2258.

Churchman, C. W. (1952). Ethics, ideals and dissatisfaction. Ethics, 63(1), 64-65.

Churchman, C. W. (1970). Operations research as a profession. Management Science, 17(2), B-37-53.

Churchman, C. W. \& Ackoff, R. L. (1949). The democratization of philosophy. Science \& Society, 13(4), 327-339.

Clouder, D. L., Davies, B., Sams, M. and McFarland, L., (2012). “Understanding where you're coming from": Discovering an [inter] professional identity through becoming a peer facilitator. Journal of Interprofessional Care, 26(6), 459-464.

Cohen, C. \& Midgley, G. (1994). The North Humberside diversion from custody project for mentally disordered offenders: Research report. Hull: Centre for Systems Studies.

Collins, B. (2015). Intentional whole health system redesign. Southcentral Foundation's 'Nuka' system of care. Retrieved from: https://www. kingsfund. org. uk/sites/files/kf/field/field_publication_file/ intentional-whole-health-system-redesign-Kings-Fund-November-2015.pdf

Commission on Social Determinants of Health. (2008). Closing the gap in a generation: health equity through action on the social determinants of health. Final Report of the Commission on Social Determinants of Health. Geneva: World Health Organization.

Coram, R. \& Burnes, B. (2001). Managing organisational change in the public sector. Lessons from the privatisation of the Property Service Agency. International Journal of Public Sector Management, 14(2), 94-110.

Córdoba, J. R. (2001). A critical systems thinking approach for the planning of information technology in the information society. Hull: Doctoral Thesis. 
Córdoba, J. R. \& Midgley, G. (2006). Broadening the boundaries: an application of critical systems thinking to IS planning in Colombia. Journal of the Operational Research Society, 57(9), 1064-1080.

Costello, C. Y. (2005). Professional identity crisis: Race, class, gender, and success at professional schools. Nashville: Vanderbilt University Press.

Cox, S. M., Brett-MacLean, P. and Courneya, C. A., (2016). "My turbinado sugar": Art-making, wellbeing and professional identity in medical education. Arts \& Health, 8(1),65-81.

Coyle, E. (2012). The annual report of the Director of Public Health. Kirkcaldy: NHS Fife.

Cruess, R. L., Cruess, S. R. and Steinert, Y., (2016). Amending Miller's pyramid to include professional identity formation. Academic Medicine, 91(2), pp. 180-185.

Currie, G., Lockett, A., Finn, R., Martin, G. \& Waring, J, (2012). Institutional work to Maintain Professional Power: Recreating the Model of Medical Professionalism. Organisation Studies, 33(7), pp. 037-962

Davies, S. (2013). Annual Report of the Chief Medical Officer, Volume 2: Infections and the rise of antimicrobial resistance. London: Department of Health.

Deming, W. (1982). Out of the crisis. Cambridge: Massachusetts Institute of Technology.

Derryberry, M. (1957). Health education in transition. American Journal of Public Health, 47(11), 1357-1366.

Drummond-Hay, R.,\& Bamford, D. (2009). A case study into planning and change management within the UK National Health Service. International Journal of Public Sector Management, 22(4), 324-337.

Dutton, J. E., Dukerich, J. M. and Harquail, C. V. (1994). Organizational images and member identification. Administrative Science Quarterly, 39(2), 239-263.

Ferlie, E., McGivern, G. \& Fitzgerald, L. (2012). A new mode of organising in health care? Governmentality and managed networks in cancer services in England. Social Science \& Medicine, 74(3), 340-347.

Frerichs, L., Hassmiller Lich, K., Dave, G. \& Corbie-Smith, G. (2016). Integrating systems science and community-based participatory research to achieve health equity. American Journal of Public Health, 106(2), 215-222.

Friend, J. (1994). Community involvement in health strategy in Tower Hamlets. In C. Ritchie, A. Taket \& J. Bryant (Eds.), Community works: 26 case studies showing Operational Research in action (pp. 137-145). Sheffield: Pavic Publications.

Gilleard, C. (2008). A murderous ageism? Age, death and Dr. Shipman. Journal of Aging Studies, 22(1), 88-95.

Gomes, B., Harding, R., Foley, K. M. \& Higginson, I. J. (2009). Optimal approaches to the health economics of palliative care: Report of an international think tank. Journal of Pain and Symptom Management, 38(1), 4-10. 
Gottlieb, K. (2013). The Nuka System of Care: Improving health through ownership and relationships. International Journal of Circumpolar Health, 72(1), 1-6.

Gregory, W., Romm, N. \& Walsh, M. (1994). The Trent Quality Initiative: A multi-agency evaluation of quality standards in the National Health Service. Hull: Centre for Systems Studies.

Gretton, C. \& Honeyman, M. (2016). The digital revolution: Eight technologies that will change health and care. The King's Fund. Retrieved from http://www. kingsfund. org. uk/publications/ articles/eight-technologies-will-change-health-and-care

Haslam, S. A. (2004). Psychology in organizations. The social identity approach. London: Sage.

Helfgott, A. (2017). Resilience, systems thinking and development: towards an operational framework for systemic resilience with applications for community operational research. European Journal of Operational Research, under review.

Helmich, E., Yeh, H. M., Kalet, A. and Al-Eraky, M., (2017). Becoming a doctor in different cultures: Toward a cross-cultural approach to supporting professional identity formation in medicine. Academic Medicine, 92(1),58-62.

Ibarra, H. (1999). Provisional selves: Experimenting with image and identity in professional adaptation. Administrative Science Quarterly 44 (4), 764-791

Institute of Medicine. (2001). Crossing the quality chasm: A new health system for the 21st century. Washington: National Academy Press.

Intergovernmental Panel on Climate Change. (2015). Climate change 2014 synthesis report. Contribution of working groups I, II and III. Geneva: Intergovernmental Panel on Climate Change.

Johnson, M. P. (2011). Community-based operations research: Decision modelling for local impact and diverse populations. New York: Springer.

Kazemi M., Carrer A., Moimas S., Zandonà L., Bussani R., Casagranda B., Palmisano S., Prelazzi P., Giacca M., Zentilin L., De Manzini N., Giacca M. \& Zacchigna S., (2016). VEGF121 and VEGF165 differentially promote vessel maturation and tumor growth in mice and humans. Cancer Gene Therapy, 23(5), 125-132.

Kittler, M. G. (2017) Do we understand each other? Discussing academic exchange from a crosscultural communication perspective. ISMO, forthcoming.

Marmot, M. \& Bell, R. (2012). Fair society, healthy lives. Public Health, 126 (S1), S4-10.

Mason, A. \& Kittler, M. (2010). Person-centred healthcare in CMHTs: Developing the delivery of person-centred healthcare in CMHTs taking a collaborative perspective. Inverness: NHS Highland.

McCannon, C. J., Hackbarth, A. D. \& Griffin, F. A. (2007). Miles to go: An introduction to the 5 million lives campaign. The Joint Commission Journal on Quality and Patient Safety, 33(8), 477-484.

Midgley, G. (1992). The sacred and profane in critical systems thinking. Systems Practice, 5(1), 5-16. 
Midgley, G. (2000). Systemic intervention: Philosophy, methodology, and practice. New York: Kluwer/Plenum.

Midgley, G. (2006). Systemic intervention for public health. American Journal of Public Health,_96(3), 466-472.

Midgley, G., Ahuriri-Driscoll, A., Baker, V., Foote, J., Hepi, M., Taimona, H., Rogers-Koroheke, M., Gregor, J., Gregory, W., Lange, M., Veth, J., Winstanley, A. \& Wood, D. (2007). Practitioner identity in systemic intervention: Reflections on the promotion of environmental health through Māori community development. Systems Research and Behavioral Science, 24(2), 233-247.

Midgley, G. \& Milne, A. (1995). Creating employment opportunities for people with mental health problems: A feasibility study for new initiatives. The Journal of the Operational Research Society, $46(1), 35-42$.

Midgley, G., Munlo, I. \& Brown, M. (1998). The theory and practice of boundary critique: Developing housing services for older people. Journal of the Operational Research Society, 49(5), 467-478.

Midgley, G. \& Ochoa-Arias, A. E. (2004). Community operational research: OR and systems thinking for community development. New York: Springer.

Midgley G \& Pinzón L (2013). Systemic Mediation: Moral Reasoning and Boundaries of Concern. Systems Research and Behavioral Science, 30, 607-632.

Midgley, G. \& Reynolds, M. (2004). Community and environmental OR: Towards a new agenda. In: In G. Midgley \& A. E. Ochoa-Arias (Eds.), Community operational research: OR and systems thinking for community development (pp. 297-316.). New York: Springer.

Moss, J. M., Gibson, D. M. and Dollarhide, C. T. (2014). Professional identity development: A grounded theory of transformational tasks of counselors. Journal of Counseling \& Development, 92(1), 3-12.

Moullin, M. (1994). Getting planners to take notice: Influence the design of a new maternity unit. In C. Ritchie, A. Taket \& J. Bryant (Eds.), Community works: 26 case studies showing Operational Research in action (pp. 146-153). Sheffield: Pavic Publications.

National Audit Office. (2017). Health and social care integration. London: NAO.

Navarro, V. (2009). What we mean by social determinants of health. International Journal of Health Services, 39(3), 423-441.

Naylor, C. \& Curry, N. (2015). Transforming our health care system: Ten priorities for commissioners. The King's Fund. Retrieved from: https://www. kingsfund. org. uk/sites/files/kf/field/field_publica tion_file/10PrioritiesFinal2.pdf

NHS England. (2014). Integrated care and support pioneers. Annual report. Wakefield: NHS England.

NHS England. (2016). NHS operational planning and contracting guidance 2017-2019. Wakefield: NHS England. 
North West London Collaboration of Clinical Commissioning Groups. (2017). North West London sustainability and transformation plan summary - Being well, living well. Retrieved from https://www. england. nhs. uk/stps/ view-stps/\#london.

Nyswander, D. (1956). Education for health: some principles and their application. Health Education Monographs, 14(1), 58-70.

Pepper, A. (1994). Needs Assessment for British League Against Rheumatism. In C. Ritchie, A. Taket \& J. Bryant (Eds.), Community works: 26 case studies showing Operational Research in action (pp. 6974). Sheffield: Pavic Publications.

Postmes, T., Haslam, S. A. \& Swaab, R. I. (2005). Social influence in small groups: An interactive model of social identity formation. European Review of Social Psychology, 16(1), 1-42.

Powell, A., Rushmer, R. \& Davies, H. (2009). A systematic narrative review of quality improvement models in health care. Edinburgh: NHS Quality Improvement Scotland.

Ritchie, C., Taket, A. \& Bryant, J. (1994). Community works: 26 case studies showing operational research in action. Sheffield: Pavic Publications.

Roberts M. J., Hsiao, W., Berman, P. \& Reich, M. R. (2002). Getting health reform right. Oxford: Oxford University Press.

Rosenhead J (1986). Custom and practice. Journal of the Operational Research Society, 37(4), 335343.

Scottish Government. (2007). Better health, better care: Action plan. Edinburgh: Scottish Government. Retrieved from http://www. scotland. gov. uk/Publications/2007/12/11103453/0

Shen, C. -Y. \& Midgley, G. (2007). Toward a Buddhist systems methodology 3: An application in a Taiwanese non-governmental organization. Systemic Practice and Action Research, 20(3), 211-244.

Smith, H. K., Harper, P. R., Potts, C. N. \& Thyle, A. (2009). Planning sustainable community health schemes in rural areas of developing countries. European Journal of Operational Research, 193(3), 768-777.

Sommer, K. A. \& Mabin, V. J. (2015). Insights into the eldercare conundrum through complementary lenses of Boardman's SSM and TOC's Evaporating Cloud. European Journal of Operational Research, 248(1). 286-300.

Tajfel, H. \& Turner, J. C., (1979). An integrative theory of intergroup conflict. The social psychology of intergroup relations. In W. Austin \& S. Worchel (Eds.), The social psychology of intergroup relations (pp. 33-47). Monterey: Brooks-Cole.

Tajfel, H. \& Turner, J. C., (1986) The social identity theory of intergroup behavior. In S. Worchel \& W. G. Austin (Eds.), Psychology of intergroup relations (pp. 7-24). Chicago: Nelson-Hall.

Taket, A. (1994). Evaluation in the Health Service. In C. Ritchie, A. Taket \& J. Bryant (Eds.), Community works: 26 case studies showing Operational Research in action (pp. 211-219). Sheffield: Pavic Publications. 
Taket, A. \& White, L. (2004). Playing with PANDA: The CybOrg and the Rhizome. In G. Midgley \& A. E. Ochoa-Arias (Eds.), Community operational research: OR and systems thinking for community development (pp. 253-272). New York: Springer.

Thornberg, R. (2012). Informed grounded theory. Scandinavian Journal of Educational Research, 56(3), 243-259.

Thorne, M. L. (2002). Colonizing the new world of NHS management: The shifting power of professionals. Health Services Management Research, 15(1), 14-26.

Turner, J. C., (1975). Social comparison and social identity: Some prospects for intergroup behaviour. European Journal of Social Psychology, 5(1), pp. 1-34.

Ufua DE, Papadopoulos T and Midgley G (2017). Systemic lean intervention: Enhancing lean with community operational research. European Journal of Operational Research, under review.

US Government. (2012). GHI principle paper: Health systems strengthening, draft 6: Global health initiative. Retrieved from www. ghi. gov/principles/docs/principle PaperHSS.pdf

Vahl, M. (1994). Evaluation of Community Resource Teams in North Humberside. In C. Ritchie, A. Taket \& J. Bryant (Eds.), Community works: 26 case studies showing Operational Research in action (pp. 220-226). Sheffield: Pavic Publications.

Van Knippenberg, D. and Hogg, M. A. (2003). Leadership and power: Identity processes in groups and organizations. London: Sage.

Walsh, M. \& Hostick, T. (2004). Improving health care through community OR. Journal of the Operational Research Society, 56(2), 193-201.

Waltner-Toews, D., Kay, J., Murray, T. P. \& Neudoerffer, C. (2004). Adaptive Methodology for Ecosystem Sustainability and Health (AMESH): An Introduction. In G. Midgley \& A. E. Ochoa-Arias (Eds.), Community operational research: OR and systems thinking for community development (pp. 317-349). New York: Springer.

Warrender, C. (2016). Politician warns cutting $£ 30$ million from NHS Fife budget will leave it in 'critical condition'. The Courier. Retrieved from https://www. thecourier. co. uk/fp/news/local/ fife/162354/politician-warns-cutting-30-million-nhs-fife-budget-will-leave-critical-condition/

Weiner, J. P., Yeh, S. \& Blumenthal, D. (2013). The impact of health information technology and ehealth on the future demand for physician services. Health Affairs, 32(11), 1998-2004.

World Health Organisation. (2007). Everybody's business strengthening health systems to improve health outcomes who's frame work for action. Geneva: World Health Organization.

World Health Organisation. (2008). WHO surgical safety checklist and implementation manual. Retrieved from http://www. who. int/patientsafety/safesurgery/ss_checklist/en/

World Health Organisation. (2014). Antimicrobial resistance global report on surveillance. Geneva: World Health Organization. 


\section{Table 1}

Themes underlying the opposition towards a novel approach.

\begin{tabular}{|c|c|c|}
\hline Theme & Characteristic & Interview excerpt \\
\hline Shifting Culture & $\begin{array}{l}\text { Changing expectations, } \\
\text { practicalities of running a business, } \\
\text { generational shifts }\end{array}$ & $\begin{array}{l}\text { "I think society is becoming more } \\
\text { demanding generally so possibly that's } \\
\text { just an aspect... which also includes their } \\
\text { expectations of general practice". } \\
\text { "...patients want to be seen when they } \\
\text { want to be seen at the time which suits } \\
\text { them..." }\end{array}$ \\
\hline $\begin{array}{l}\text { Maintaining } \\
\text { Professionalism }\end{array}$ & $\begin{array}{l}\text { Avoiding changes - practical or } \\
\text { concrete- to previously held norms } \\
\text { and maintaining existing } \\
\text { professional attitudes }\end{array}$ & $\begin{array}{l}\text { "...it's hard to be a GP at the moment } \\
\text { because you can see that things are } \\
\text { changing and if you're a GP you know } \\
\text { some of the change isn't good". } \\
\text { "...there is a limit to how much general } \\
\text { practice can take on [without } \\
\text { compromising quality]..." }\end{array}$ \\
\hline $\begin{array}{l}\text { Resisting De- } \\
\text { professionalism }\end{array}$ & $\begin{array}{l}\text { Protecting boundaries through } \\
\text { professionalism, traditionalism, } \\
\text { autonomy and control }\end{array}$ & $\begin{array}{l}\text { "I have been going on for } 15 \text { years } \\
\text { about being a nurse partner and people } \\
\text { (GPs) just laugh at me, say oh no we } \\
\text { don't want that, it wouldn't work". } \\
\text { "... why would we want to pay a nurse } \\
\text { partner who hasn't done the same } \\
\text { training as us...?" }\end{array}$ \\
\hline
\end{tabular}




\section{Table 2}

Midgley, Ahuriri-Driscoll, Baker et al (2007) indicative strategies and omissions in the NUKA Trial

\begin{tabular}{|c|c|c|}
\hline Strategy for Critical Reflection on Identity & $\begin{array}{c}\text { NUKA } \\
\text { Alaska, US }\end{array}$ & $\begin{array}{l}\text { NUKA Trial } \\
\text { Scotland, UK }\end{array}$ \\
\hline $\begin{array}{l}\text { Exploring the relevance of culture (and categories of } \\
\text { identity). }\end{array}$ & $P(S)$ & NP \\
\hline $\begin{array}{l}\text { Allowing sufficient time for relationship building prior to } \\
\text { and during substantive intervention. }\end{array}$ & $P(S)$ & NP \\
\hline $\begin{array}{l}\text { Using established formal as well as informal processes } \\
\text { for sharing information about identity. }\end{array}$ & Unclear & NP \\
\hline $\begin{array}{l}\text { Establishing a strategic partnership with a trusted } \\
\text { organization. }\end{array}$ & $\mathrm{N}$ & $P(N S)$ \\
\hline $\begin{array}{l}\text { Involving trusted individuals in brokering new } \\
\text { relationships. }\end{array}$ & $P(S)$ & $P(N S)$ \\
\hline $\begin{array}{l}\text { Ensuring that people with a valued local identity and } \\
\text { local knowledge are key decision makers [... allowing } \\
\text { insider/outsider boundaries to be blurred. }\end{array}$ & $P(S)$ & $P(N S)$ \\
\hline $\begin{array}{l}\text { Recruiting a person to the practitioner team whose } \\
\text { identity is closely aligned with that of participants. }\end{array}$ & $P(S)$ & NP \\
\hline $\begin{array}{l}\text { Adopting methodological principles that align with } \\
\text { participants' identities. }\end{array}$ & $P(S)$ & NP \\
\hline $\begin{array}{l}\text { Using a participative approach to establish an active } \\
\text { listening stance. }\end{array}$ & $P(S)$ & $P(N S)$ \\
\hline $\begin{array}{l}\text { Involving participants in the choice and/or design of } \\
\text { methods in addition to involving them in the } \\
\text { conversations that the methods structure. }\end{array}$ & $P(S)$ & NP \\
\hline $\begin{array}{l}\text { Sincerely mirroring key aspects of participants' concerns } \\
\text { and interests associated with their identity. }\end{array}$ & $P(S)$ & NP \\
\hline $\begin{array}{l}\text { Identifying what the participants are looking for in } \\
\text { evaluating identity and (sincerely) framing practitioners' } \\
\text { presentations of self accordingly. }\end{array}$ & $P(S)$ & NP \\
\hline
\end{tabular}

Key: $\mathrm{P}=$ Present, NP = Not present, $(\mathrm{S})=$ Sufficient, $(\mathrm{NS})$ = Not Sufficient

NB: The table identifies rather than quantifies important omissions and adds an indicative evaluation of the relative sufficiency of each factor when present. 